\title{
Stress Tolerance and Virulence-Related Roles of Lipopolysaccharide in Burkholderia glumae
}

\author{
Chaeyeong Lee ${ }^{1,2 \dagger}$, Mohamed Mannaa ${ }^{1,2 \dagger}$, Namgyu Kim ${ }^{1,2}$, Juyun Kim ${ }^{1,2}$, Yeounju Choi ${ }^{1,2}$, Soo Hyun Kim ${ }^{1,2}$, \\ Boknam Jung, ${ }^{3}$, Hyun-Hee Lee ${ }^{1,2}$, Jungkwan Lee ${ }^{3}$, and Young-Su Seo (iD) ${ }^{1,2 \%}$ \\ ${ }^{1}$ Department of Microbiology, Pusan National University, Busan 46241, Korea \\ ${ }^{2}$ Department of Integrated Biological Science, Pusan National University, Busan 46241, Korea \\ ${ }^{3}$ Department of Applied Biology, Dong-A University, Busan 49315, Korea
}

(Received on April 29, 2019; Revised on June 26, 2019; Accepted on July 2, 2019)

The lipopolysaccharide (LPS) composed of lipid A, core, and $\mathrm{O}$-antigen is the fundamental constituent of the outer membrane in gram-negative bacteria. This study was conducted to investigate the roles of LPS in Burkholderia glumae, the phytopathogen causing bacterial panicle blight and seedling rot in rice. To study the roles of the core oligosaccharide (OS) and the $\mathrm{O}$ antigen region, mutant strains targeting the warC and the wbiFGHI genes were generated. The LPS profile was greatly affected by disruption of the waaC gene and slight reductions were observed in the $\mathrm{O}$-antigen region following wbiFGHI deletions. The results indicated that disruption in the core OS biosynthesis-related gene, waaC, was associated with increased sensitivity to environmental stress conditions including acidic, osmotic, saline, and detergent stress, and to polymyxin B. Moreover, significant impairment in the swimming and swarming motility and attenuation of bacterial virulence to rice were also observed in the waaC-defective mutant. The motility and virulence of $\mathrm{O}$-antigen $\mathrm{mu}-$ tants defective in any gene of the wbiFGHI operon, were not significantly different from the wild-type except in

\footnotetext{
${ }^{\dagger}$ These authors contributed equally to this work.

*Corresponding author.

Phone) +82-51-510-2267, FAX) +82-51-514-1778

E-mail)yseo2011@pusan.ac.kr

ORCID

Young-Su Seo

https://orcid.org/0000-0001-9191-1405

(c) This is an Open Access article distributed under the terms of the Creative Commons Attribution Non-Commercial License (http:// creativecommons.org/licenses/by-nc/4.0) which permits unrestricted noncommercial use, distribution, and reproduction in any medium, provided the original work is properly cited.
}

Articles can be freely viewed online at www.ppjonline.org. slight decrease in swimming and swarming motility with wbiH deletion. Altogether, the results of present study indicated that the LPS, particularly the core OS region, is required for tolerance to environmental stress and full virulence in B. glumae. To our knowledge, this is the first functional study of LPS in a plant pathogenic Burkholderia sp. and presents a step forward toward full understanding of B. glumae pathogenesis.

Keywords : Burkholderia glumae, lipopolysaccharide, stress tolerance, virulence

Handling Editor : Han, Sang-Wook

The outer membrane of gram-negative bacteria is composed mainly of lipopolysaccharide (LPS) with attached integral proteins that together orchestrate the flux of hydrophilic and hydrophobic molecules across the membrane. As the fundamental component of cellular outer membrane, accounting for around three-quarters of the surface of most gram-negative bacteria, the LPS is responsible for many functions as a barrier to environmental stress and signaling machinery (Sperandeo et al., 2017).

LPS of gram-negative bacteria is composed of three parts: lipid A, core oligosaccharide (OS), and O-antigen (Dong et al., 2017). Lipid A, the most structurally conserved region of LPS is the hydrophobic moiety, which anchors LPS to the outer membrane. The core OS is composed of non-repeating sugars that link lipid A to the Oantigen portion. The core OS is divided into two parts, an outer-core OS with variable structure that attaches to the Oantigen and an inner-core OS with a more conserved structure, that attaches to lipid A. The inner-core OS is mainly composed of 3-deoxy-D-manno-oct-2-ulosonic acid (Kdo) 
and L-glycero-D-manno-heptose (heptose) (Holst, 2007). The O-antigen is the outermost portion of LPS and is composed of a variable number of repeated OS units, greatly varying between different bacterial strains (Sperandeo et al., 2017).

LPS not only provides cellular stability and protection from harsh environments but is also responsible for numerous interactions and exerts multiple signaling-related roles that are critical for pathogenicity to mammalian and plant cells (Kutschera and Ranf, 2018). The induction of cellular responses upon the recognition of bacterial LPS by mammalian cells has been described in previous studies (Park and Lee, 2013). However, the recognition of bacterial LPS by plant cells and the subsequent cell responses remain comparatively elusive (Vilakazi et al., 2017). Previous studies characterized the action of bacterial LPS as an elicitor of the plant innate immune system, triggering the production of antimicrobial compounds, reactive oxygen species, or pathogenesis-related proteins (Finnegan et al., 2016; Newman et al., 2013; Zeidler et al., 2004).

Studies involving the generation of mutant strains defective in LPS biosynthesis-related genes have indicated the requirement of LPS for bacterial virulence and resistance to various stress conditions. In particular, mutations resulting in alterations of the LPS structure were found to be associated with changes in biofilm formation, colonization of host tissues, and virulence of Escherichia coli (Møller et al., 2003; Nakao et al., 2012). Salmonella enterica was shown to lose its virulence as a consequence of mutations in LPS biosynthesis-related genes (Kong et al., 2011). In Burkholderia cenocepacia, the complete core OS was found to be required for bacterial resistance to antimicrobial peptides, as well as for virulence to model animals (Loutet et al., 2006). It was later reported that the addition of 4-amino-4-deoxy-L-arabinose (L-Ara4N) to the LPS was very critical for the intrinsic resistance to antimicrobial peptides (Hamad et al., 2012).

Although many studies were conducted to characterize the functions of LPS in human and animal pathogenic gram-negative bacteria, only few have addressed the role of LPS in plant pathogenic bacteria. LPS-defective mutants of the wilt pathogen Pseudomonas solanacearum showed reduced virulence to tobacco plants (Hendrick and Sequeira, 1984). In the phytopathogen Erwinia sp., loss of virulence and unsuccessful invasion were reported in mutants with altered LPS structure (Schoonejans et al., 1987). In Xanthomonas campestris, defects in two genes involved in LPS core OS biosynthesis resulted in altered behavior and attenuation of virulence (Dow et al., 1995). More recently, the LPS of phytopathogenic Xanthomonas oryzae was found to be required for the type III secretion system and, consequently, for bacterial virulence (Wang et al., 2013).

Burkholderia glumae, a gram-negative phytopathogenic bacterium in the Burkholderia sensu stricto lineage, is the etiological agent of a serious disease threatening rice cultivation worldwide (Ham et al., 2011). Previous studies have investigated the disease-causing mechanisms, and several virulence factors (e.g., bacterial motility, secretion systems, exopolysaccharide [EPS], toxoflavin, and virulence-related enzymes such as metalloprotease) have been identified (Jeong et al., 2011; Jung et al., 2018; Kim et al., 2007; Lee et al., 2016; Lelis et al., 2019; Mannaa et al., 2019). The role of LPS in relation to virulence or adaptation to environmental stress has not yet been investigated in B. glumae. Therefore, this study was conducted to address the question whether the LPS of B. glumae is implicated in tolerance to harsh environment and/or virulence to rice.

\section{Materials and Methods}

Bacterial strains and culture conditions. The bacterial strains and plasmids used in this study are listed in Table 1. The rice pathogenic $B$. glumae BGR1 (wild-type), the generated mutant strains, and $E$. coli were grown at $37^{\circ} \mathrm{C}$ in Luria-Bertani (LB) media. Appropriate antibiotics were added to the culture media, according to the purpose, at the following concentrations: rifampicin, $50 \mu \mathrm{g} / \mathrm{ml}$; kanamycin, 30 or $50 \mu \mathrm{g} / \mathrm{ml}$; tetracycline, $10 \mu \mathrm{g} / \mathrm{ml}$.

Molecular techniques for mutant strain generation. Standard protocols were used for DNA amplification, recombinant DNA construction, and mutant strain generation (Sambrook et al., 1989). To amplify the upstream region (L fragment) and the downstream region ( $\mathrm{R}$ fragment) of the target genes (wbiF, wbiG, wbiH, and wbil) for deletion mutant generation, the genomic DNA (gDNA) of B. glumae BGR1 was extracted and polymerase chain reaction (PCR) was performed using Solgent Pfu-X DNA polymerase (Solgent, Daejeon, Korea) with primer pairs containing appropriate restriction sites (Supplementary Table 1). The amplified fragments and $\mathrm{pK} 18$ mobsacB suicide vector were digested with the appropriate restriction enzymes and ligated using T4 DNA ligase (Schäfer et al., 1994). Competent $E$. coli DH5 a $\lambda$ pir cells were transformed with the recombinant plasmids for amplification. Amplified plasmids were extracted, reintroduced into E. coli S17-1 $\lambda$ pir (donor strain), and subsequently used to transform $B$. glumae BGR1 (recipient strain) by bi-parental mating (Simon et al., 1983). After selection of transformed B. glumae BGR1 using appropriate antibiotics, the deletion mutants 
Table 1. Bacterial strains and plasmids

\begin{tabular}{|c|c|c|}
\hline Strains or plasmid & Characteristic & Reference \\
\hline \multicolumn{3}{|c|}{ Burkholderia glumae } \\
\hline BGR1 & Wild-type, Rif ${ }^{r}$ & Jeong et al. (2003) \\
\hline BGS2 & BGR1 tofI:: $\Omega$ & Kim et al. (2004) \\
\hline$\Delta$ wbiF & BGR1 $\Delta w b i F$, Rif $^{r}$ & This study \\
\hline$\Delta$ wbiG & BGR1 $\Delta w b i G$, Rif $^{r}$ & This study \\
\hline$\Delta$ wbiH & BGR1 $\Delta w b i H$, Rif $^{r}$ & This study \\
\hline$\Delta$ wbiI & BGR1 $\Delta w b i I$, Rif $^{x}$ & This study \\
\hline$\Delta$ waaC & 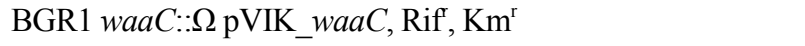 & This study \\
\hline $\mathrm{c} \Delta w b i F$ & $\Delta w b i F$ containing $\mathrm{pBBR} \_w b i F, \mathrm{Rif}^{\mathrm{r}}$ & This study \\
\hline $\mathrm{c} \Delta w b i G$ & $\Delta w b i G$ containing $\mathrm{pBBR} \_w b i G, \mathrm{Rif}^{\mathrm{r}}$ & This study \\
\hline $\mathrm{c} \Delta w b i H$ & $\Delta w b i H$ containing $\mathrm{pBBR} \_w b i H, \mathrm{Rif}^{\mathrm{r}}$ & This study \\
\hline $\mathrm{c} \Delta w b i I$ & $\Delta w b i I$ containing $\mathrm{pBBR} \_w b i I, \mathrm{Rif}^{\mathrm{r}}$ & This study \\
\hline $\mathrm{c} \Delta w a a C$ & $\Delta w a a C$ containing $\mathrm{pRK} \_w a a C$, $\mathrm{Rif}^{\mathrm{r}}, \mathrm{Km}^{\mathrm{r}}$ & This study \\
\hline \multicolumn{3}{|l|}{ Escherichia coli } \\
\hline DH5 $\alpha \lambda$ pir & E. coli used for cloning and replication of plasmids & Lab collection \\
\hline S17-1 $\lambda$ pir & E. coli used for transferring cloning plasmids to recipient cells & Lab collection \\
\hline \multicolumn{3}{|l|}{ Plasmids } \\
\hline pk18mobsacB & Allelic exchange suicide vector, $s a c B, \mathrm{Km}^{\mathrm{r}}$ & Schäfer et al. (1994) \\
\hline pVIK112 & R6K suicide vector, lac $Z Y$ for transcriptional fusion, $\mathrm{Km}^{\mathrm{r}}$ & Kalogeraki and Winans (1997) \\
\hline pBBR1MCS-2 & Broad host range expression vector, $\mathrm{Km}^{\mathrm{r}}$ & Kovach et al. (1995) \\
\hline pRK415 & Broad host range expression vector, $\mathrm{Tc}^{\mathrm{r}}$ & Keen et al. (1988) \\
\hline pVIK_waaC & pVIK1 12 vector cloning internal region of waaC & This study \\
\hline pK18_wbiF & pK18mobsacB vector cloning LR fragment of $w b i F$ & This study \\
\hline pK18_wbiG & pK18mobsacB vector cloning LR fragment of $w b i G$ & This study \\
\hline pK18_wbiH & pK18mobsacB vector cloning LR fragment of $w b i H$ & This study \\
\hline pK18_wbiI & pK18mobsacB vector cloning LR fragment of $w b i I$ & This study \\
\hline pBBR_wbiF & pBBR1MCS-2 vector including $w b i F$ gene & This study \\
\hline pBBR_wbiG & pBBR1MCS-2 vector including $w b i G$ gene & This study \\
\hline pBBR_wbiH & pBBR1MCS-2 vector including wbiH gene & This study \\
\hline pBBR_wbiI & pBBR1MCS-2 vector including wbiI gene & This study \\
\hline pRK_waaC & pRK415 vector including waaC gene & This study \\
\hline
\end{tabular}

Rif, rifampicin; Km, kanamycin; Tc, tetracycline.

were obtained after a second homologous recombination by sub-culturing in LB containing 30\% sucrose (w/v).

To generate mutant strain defective in waaC gene, the target gene was amplified by Pfu-X DNA polymerase and the appropriate restriction sites were added to the $5^{\prime}$ end region of the target gene PCR primers, waaC_F and waaC_R (Supplementary Table 1). The amplified fragments and the suicide vector pVIK112 were digested using appropriate restriction enzymes and ligated using T4 DNA ligase (Kalogeraki and Winans, 1997). Amplification of the recombinant plasmid and transformation of the B. glumae BGR1 were performed as described above. Mutant BGR1 strain was selected on LB plates containing kanamycin $(100 \mu \mathrm{g} / \mathrm{ml})$ and rifampicin $(100 \mu \mathrm{g} / \mathrm{ml})$, then confirmed by PCR with the specific primers, Lacfuse_R and waaC_
up_F designed to bind outside the EcoRI and $K p n I$ sites of pVIK112 (Supplementary Table 1). A schematic diagram for the generation of mutants is shown in Supplementary Fig. 1.

To generate the complemented strains for each deleted or disrupted gene, the complete open reading frame was amplified using appropriate primers (Supplementary Table 1) and inserted into pRK415 or pBBR1MCS-2 expression vectors (Keen et al., 1988; Kovach et al., 1995). Recombinant vectors were introduced into each mutant by conjugation. All generated mutants and complemented strains were confirmed by PCR assays. The growth rate of the generated mutant strains was compared to that of the wild-type by measuring the optical density $\left(\mathrm{OD}_{600}\right)$ in freshly inoculated LB broth every $6 \mathrm{~h}$. 
LPS electrophoretic analysis. Total LPS from B. glumae BGR1 wild-type, the generated mutants, and complemented mutants were extracted using the modified hot phenol method (Kim et al., 2017; Westphal, 1965). Briefly, bacterial cultures in $\mathrm{LB}$ were grown to $\mathrm{OD}_{600}=1.0$, harvested, washed, and resuspended in $4 \mathrm{ml}$ of $10 \mathrm{mM}$ phosphate buffer. An equal $(4 \mathrm{ml})$ volume of hot phenol was added to the cell suspensions and incubated for $1 \mathrm{~h}$ in a water bath at $65^{\circ} \mathrm{C}$ with vigorous vortexing every $5 \mathrm{~min}$. The suspension was then cooled, and $1.6 \mathrm{ml}$ of chloroform was added. The aqueous layer was then separated by centrifugation at 8,500 $\times g$ for $15 \mathrm{~min}$ and transferred to a new tube. The LPS was precipitated overnight using $10-\mathrm{ml}$ isopropyl alcohol at $-20^{\circ} \mathrm{C}$. The precipitate was washed twice in $80 \%$ ethanol, and air-dried.

For the electrophoretic analysis, the extracted LPS was suspended and heated at $95^{\circ} \mathrm{C}$ for $5 \mathrm{~min}$ in sample buffer $(80$ $\mathrm{mM}$ Tris- $\mathrm{HCl}$ [pH 6.8], 2\% sodium dodecyl sulfate [SDS], $10 \%$ glycerol, $0.0006 \%$ bromophenol blue). LPS was then separated on $15 \%$ acrylamide gel by sodium dodecyl sulfate-polyacrylamide gel electrophoresis and visualized according to the manufacturer's instructions using the Pro-Q Emerald 300 Lipopolysaccharide Gel Stain Kit (Invitrogen, Carlsbad, CA, USA).

EPS quantification assay. Quantification of EPS was performed as previously described by He et al. (2010). Briefly, bacterial cultures in Casamino acid-Peptone-Glucose medium (10 g peptone, $5 \mathrm{~g}$ glucose, $1 \mathrm{~g}$ casamino acids, 1 $\mathrm{g}$ yeast per liter) were adjusted to $\mathrm{OD}_{600}=0.4$. The supernatant was collected from $10 \mathrm{ml}$ of bacterial suspension by centrifugation at $10,000 \times g$ for $20 \mathrm{~min}$. For EPS precipitation, 2 volumes of absolute ethanol were added to the collected supernatant and incubated for $30 \mathrm{~min}$ at $-20^{\circ} \mathrm{C}$. The precipitated EPS was filtered using a vacuum pump through a membrane filter (Hyundai Micro, Anseong, Korea) and dried overnight at $55^{\circ} \mathrm{C}$. The dried EPS on the membrane filter were then quantified and expressed as $\mathrm{mg}$ per milliliter of the culture supernatant.

Environmental stress and antibiotics tolerance assays. The wild-type $B$. glumae BGR1 and the generated mutants were tested for tolerance to different environmental stresses (i.e., acidic, osmotic, saline, and oxidative stress), as previously described by Li and Wang (2011) with some modifications. Bacterial cultures in LB were grown to early exponential level $\left(\mathrm{OD}_{600}>1\right)$ and $\mathrm{OD}_{600}$ values were adjusted to 0.1. Bacterial cells were then harvested and suspended in phosphate-buffered saline. For acidity and salt stress tolerance, cells were cultured in acidic LB agar plates
$(\mathrm{pH}=4.5)$ and saline media $(1.5 \% \mathrm{NaCl})$, respectively. Tolerance to osmotic pressure was tested by adding $20 \%$ of D-sorbitol to the cell suspension and incubating for 40 min. Tolerance to oxidative stress was evaluated based on the sensitivity to $\mathrm{H}_{2} \mathrm{O}_{2}$, using disk diffusion assays on agar plates, as described in previous studies (Kim et al., 2018; King et al., 2000). In brief, LB agar plates were seeded by the tested strains and sterile paper disks pre-soaked in 30\% $\mathrm{H}_{2} \mathrm{O}_{2}$ were placed onto the center of the seeded agar plates. After a 1-day incubation at $37^{\circ} \mathrm{C}$, the clear zones around the $\mathrm{H}_{2} \mathrm{O}_{2}$ disks were measured. Bacterial sensitivity to detergent stress and antibiotics was also tested. Detergent stress tolerance was tested by adding $0.01 \%$ SDS to the cell suspension and incubating for $10 \mathrm{~min}$. The bacterial sensitivity to the antimicrobial peptide, polymyxin B, was tested using the method described by Loutet et al. (2006). Polymyxin B (Merck, Darmstadt, Germany) was added to the bacterial suspensions at a final concentration of $5 \mu \mathrm{g} / \mathrm{ml}$ and incubated for $30 \mathrm{~min}$. Except for the $\mathrm{H}_{2} \mathrm{O}_{2}$ sensitivity assay, the survival rate of the tested strains was evaluated by counting the viable cells before (T0) and after (T1) exposure to each stress condition.

Bacterial motility assays. The swimming motility assay was conducted as described elsewhere (Castelli et al., 2008). Briefly, LB plates with $0.25 \%$ agar were prepared and single colonies from each strain were inoculated using sterile toothpick into the center of the swimming plates. After incubation for $24 \mathrm{~h}$ at $37^{\circ} \mathrm{C}$, the radius of the swimming zones around the inoculation points were measured. To perform the swarming motility assay, bacterial cells from $1 \mathrm{ml}$ of LB cultures were harvested by centrifugation and resuspended in $100 \mu \mathrm{l}$ of fresh LB broth. Five microliters from each suspension were spotted onto the center of LB soft agar plates $(0.4 \%[\mathrm{w} / \mathrm{v}]$ agar $)$. The plates were then incubated for $24 \mathrm{~h}$ at $37^{\circ} \mathrm{C}$ and photographed, and the radius of the swarms were measured based on the average dendrite lengths.

Virulence assay on rice plants. Virulence assays were performed with wild-type BGR1 and generated mutants, as follows. Rice plants (Oryza sativa L. cv. Saeilmi) were grown until flowering stage under greenhouse conditions. To prepare the inocula, cells were harvested in sterile distilled water (SDW) from overnight $\mathrm{LB}$ cultures and $\mathrm{OD}_{600}$ values were adjusted. Rice panicles were inoculated by dipping in the prepared suspensions or control SDW for $1 \mathrm{~min}$. Six days after inoculation, disease severity was assessed on panicle grains based on a $0-5$ scale, as follows: 0 , clear panicle; $1,0-20 \%$ discoloration; $2,20-40 \%$ discoloration; 3 , 
40-60\% discoloration; 4, 60-80\% discoloration; and 5, 80$100 \%$ discoloration (Kim et al., 2018). After counting the number of grains at each rank, the following formula was used for disease severity:

Disease severity $=\sum$ (number of grains at each rank $\times$ rank value)/(the total number of panicles).

A disease distribution pattern was also used to further visualize the differences between treatments (Chun et al., 2009).

Statistical analysis. Each experiment was conducted at least twice with three replicates. Statistical analysis of the data was performed using the Statistical Analysis Systems (SAS Institute, Cary, NC, USA). Data from repeated experiments were tested for equality of variances using the Levene's test (Levene, 1960). Analysis of variance was performed using the GLM procedure in SAS, and the separation between means was assessed using the Tukey's honestly significant difference test, where a $P$-value of 0.05 was considered statistically significant.

\section{Results}

The wbiFGHI and waaC genes are involved in the biosynthesis of $\mathrm{O}$-antigen and core OS. The targeted genes, wbiFGHI (852, 984, 1,044, and 1,884 nt), and waaC (996 $\mathrm{nt})$, are located on chromosome 1 in the B. glumae BGR1 genome (Fig. 1A). There were no obvious differences in growth rate between the wild-type (BGR1) and the generated mutant strains ( $\Delta w b i F, \Delta w b i G, \Delta w b i H$, and $\Delta w b i I)$, except for a slight reduction in the $\triangle w a a C$ mutant, which was recovered in the complemented strain (Supplementary Fig. 2).

To test the effect of the constructed mutants on the LPS profile, electrophoretic analysis was performed. The electrophoretic analysis of LPS from the generated mutants $(\triangle w b i F, \Delta w b i G, \Delta w b i H, \Delta w b i I$, and $\triangle w a a C)$, their complemented strains (c $\Delta w b i F, \mathrm{c} \Delta w b i G, \mathrm{c} \Delta w b i H, \mathrm{c} \Delta w b i I$, and $\mathrm{c} \triangle w a a C$ ), and the wild-type (BGR1) revealed the involvement of the wbiFGHI operon and the waaC gene in the biosynthesis of the O-antigen and the core OS, respec-

A
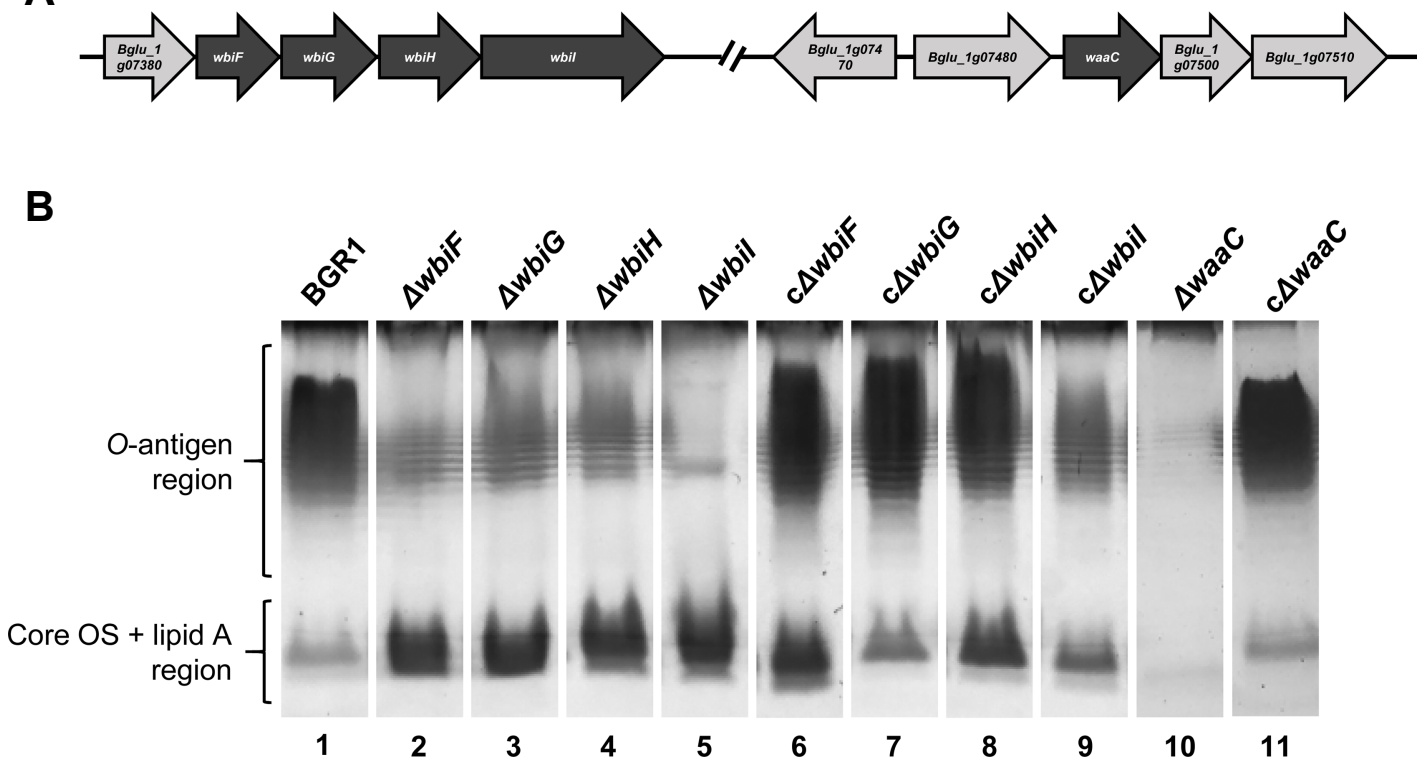

Fig. 1. Genetic organization of lipopolysaccharide (LPS) biosynthesis-related genes in Burkholderia glumae BGR1, and LPS electrophoretic analysis in wild-type and mutant strains. (A) The genes targeted for mutagenesis are involved in $\mathrm{O}$-antigen ( $w b i F$, wbiG, wbiH, and wbil) or core oligosaccharide (OS) (waaC) biosynthesis. The 5 targeted genes, indicated by dark arrows, are located on chromosome 1 of B. glumae BGR1, and are 852 nt, 984 nt, 1,044 nt, 1,884 nt, and 996 nt in length, respectively. (B) The LPS profiles of the tested strains were visualized following extraction and separation on sodium dodecyl sulfate-polyacrylamide gel electrophoresis. The typical bands of the O-antigen and lipid A + core OS regions are clearly observable in the wild-type BGR1, lane 1. Apparently incomplete O-antigen regions and highly intense core $\mathrm{OS}+$ lipid A were observed in the $\Delta w b i F, \Delta w b i G, \Delta w b i H$, and $\Delta w b i I$ mutants, lanes 2-5. The O-antigen synthesis was restored in the complementary strains, $\mathrm{c} \Delta w b i F, \mathrm{c} \Delta w b i G, \mathrm{c} \Delta w b i H$, and $\mathrm{c} \Delta w b i I$, lanes 6-9. Both O-antigen and core OS + lipid A were greatly affected in the core OS biosynthesis-related mutant $\Delta w a a C$, lane 10 . Both regions were restored in the complementary strain, $\mathrm{c} \triangle w a a C$, lane 11. 


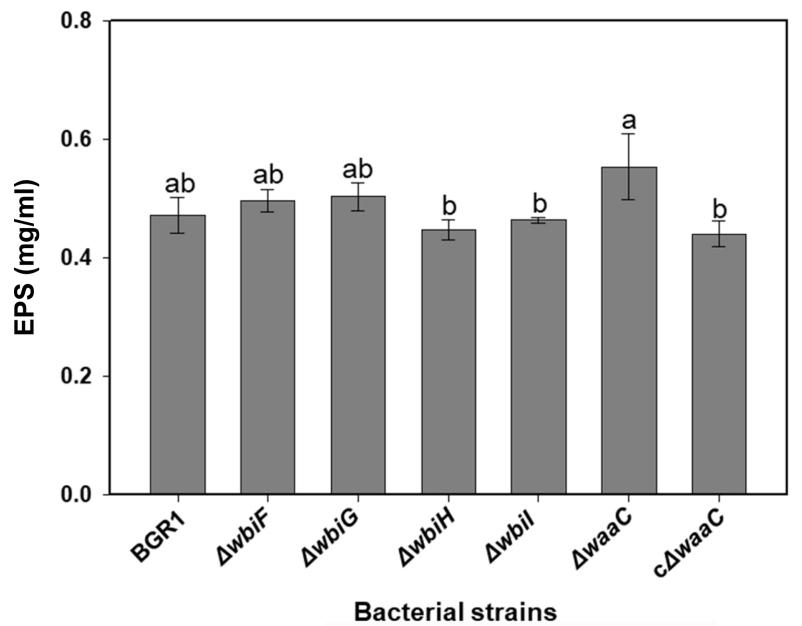

Fig. 2. Quantification of exopolysaccharide (EPS) in Burkholderia glumae BGR1 wild-type, wbiFGHI, and waaC-defective mutants. EPS extracted from wild-type $B$. glumae (BGR1) and the mutants $\Delta w b i F, \Delta w b i G, \Delta w b i H, \Delta w b i I, \Delta w a a C$, and $\mathrm{c} \Delta w a a C$ was quantified and expressed as $\mathrm{mg} / \mathrm{ml}$ of culture supernatant. No significant differences were observed in any of the mutants with respect to the wild-type. The $\triangle$ waaC mutant showed a significant EPS increase compared to both $\triangle w b i H$ and $\triangle w b i I$ mutants. The complementary strain, $\mathrm{c} \Delta w a a C$, exhibited a significantly lower EPS production compared to the $\triangle w a a C$ mutant. The different letters on the error bars represent statistically significant differences at $P<0.05$, according to Tukey's honestly significant difference test.

tively. The mutants deficient in each gene of the wbiFGHI operon showed reduced O-antigen region, with thicker core OS- and lipid A-specific bands, whereas the waaCdeficient mutant gene showed almost complete loss of both $\mathrm{O}$-antigen and core OS regions, which were restored in the complemented strains (Fig. 1B). This result indicated that the wbiFGHI operon was associated with the biosynthesis of the $\mathrm{O}$-antigen, whereas the waaC gene was essentially involved in core OS biosynthesis and also affected Oantigen assembly.

EPS production is not affected by disruption of LPS biosynthesis-related genes in B. glumae BGR1. As one of the known virulence factors of $B$. glumae, the EPS production was assessed as response to disruption in the LPS biosynthesis-related genes. The production of EPS by the mutants $\Delta w b i F, \Delta w b i G, \Delta w b i H, \Delta w b i I$, and $\triangle w a a C$ was not significantly different from $B$. glumae BGR1 wild-type. The $\triangle w a a C$ mutant produced significantly more EPS than the $\Delta w b i H$ and $\Delta w b i I$ mutants. The complemented strain, $\mathrm{c} \triangle w a a C$, showed reduced EPS production compared to the $\triangle$ waaC mutant (Fig. 2). This result suggested that EPS production was not significantly affected by mutations in the target genes with slight effect of the waaC gene when compared to the other O-antigen-related mutants, $\triangle w b i H$ and $\Delta w b i I$.

The loss of the WaaC protein is involved in tolerance to antibiotic and environmental stress in B. glumae BGR1. As one of the potential roles of LPS bacterial cells, tolerance of the generated mutants to environmental stress was assessed. The tolerance to various stress conditions was compared between the mutant strains ( $\triangle w b i F, \triangle w b i G$, $\triangle w b i H, \Delta w b i I$, and $\triangle w a a C)$ and the wild-type (BGR1). The $\triangle$ waaC mutant, showed a significant reduction in the survival rate under acidic, osmotic, and saline stress conditions (Fig. 3A, B, and C). The complemented strain $\mathrm{c} \triangle$ waaC restored normal survival to acidic and saline stress but not to osmotic stress. The sensitivity to $\mathrm{H}_{2} \mathrm{O}_{2}$ was used to assess tolerance to oxidative stress. There was no difference in bacterial sensitivity to $\mathrm{H}_{2} \mathrm{O}_{2}$ between the wild-type and all the tested mutants $(\triangle w b i F, \Delta w b i G, \Delta w b i H, \Delta w b i I$, and $\triangle w a a C$ ). Moreover, both mutants and wild-type BGR1 were significantly more tolerant to $\mathrm{H}_{2} \mathrm{O}_{2}$ stress compared to the quorum sensing (QS)-defective mutant BGS2, which was used as a negative control (Fig. 3D).

The mutants were also compared for their tolerance to detergent (SDS) stress and to the antimicrobial peptide, polymyxin B. Among the tested mutants, a significant reduction in the survival rate was only observed with the core OS defective mutant, $\triangle w a a C$. The tolerance to both SDS and polymyxin B was completely restored in the complemented strain, c $\triangle$ waaC (Fig. 4).

These results suggested that the loss of the WaaC protein causing the formation of a heptoseless LPS, resulted in more sensitivity of B. glumae BGR1 to acidic, osmotic, saline, and detergent stress conditions, and to polymyxin $\mathrm{B}$ exposure. The results also indicated that neither the $\mathrm{O}-$ antigen-related operon wbiFGHI nor the core OS-related $w a a C$ gene were related to tolerance to oxidative stress in $B$. glumae BGR1.

The loss of the WaaC protein is associated with impaired swimming and swarming motility in B. glumae BGR1. Bacterial motility is known to be linked to virulence by facilitating movements to infection sites and colonization of the host tissues. The swimming and swarming motility tested on soft agar plates showed that the waaCdefective mutant, $\triangle w a a C$, exhibited a significantly declined motility compared to the wild-type BGR1. This was clearly indicated by the reduced swimming motility diameters and swarm diameters around the inoculation spot, compared 

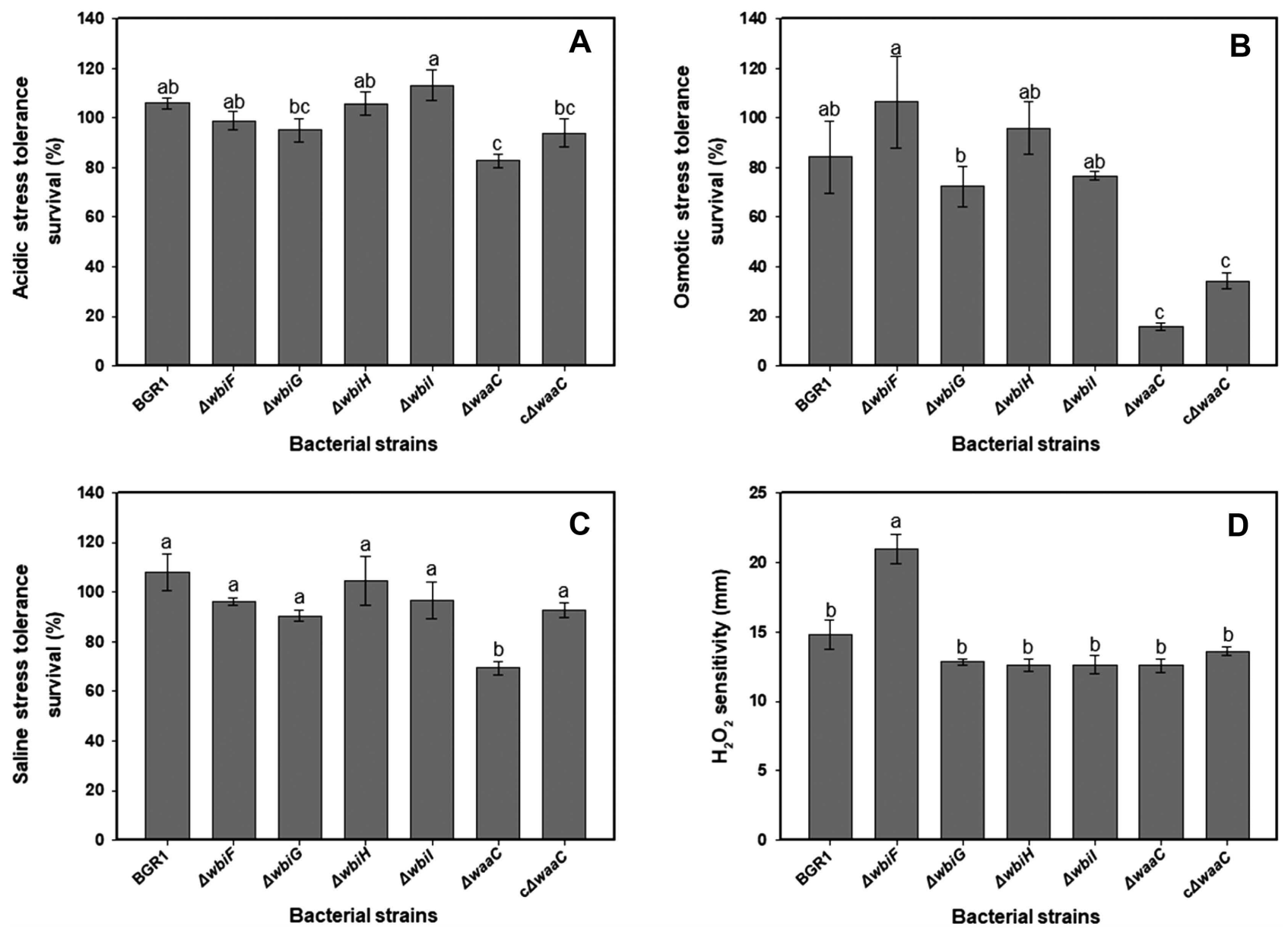

Fig. 3. Burkholderia glumae lipopolysaccharide role in adaptation to environmental stress. The wild-type BGR1 and mutant strains $\triangle w b i F, \Delta w b i G, \Delta w b i H, \Delta w b i I, \Delta w a a C$, and $\mathrm{c} \Delta w a a C$ were tested for tolerance to various environmental stresses; acidic media $(\mathrm{pH}=4.5)$ (A), osmotic stress $\left(20 \%\right.$ D-sorbitol) $(B)$, saline stress $(1.5 \% \mathrm{NaCl})(\mathrm{C})$, and oxidative stress $\left(30 \% \mathrm{H}_{2} \mathrm{O}_{2}\right)(\mathrm{D})$. The bacterial survival rate was estimated based on the difference between the bacterial population before and after exposure to the environmental stress. Tolerance to oxidative stress was evaluated as the sensitivity to $\mathrm{H}_{2} \mathrm{O}_{2}$ exposure by measuring the clear zones around paper disks previously immersed in $30 \% \mathrm{H}_{2} \mathrm{O}_{2}$, on agar plates seeded with each tested strain. The quorum sensing-defective mutant BGS2 was used as a positive control in the $\mathrm{H}_{2} \mathrm{O}_{2}$ sensitivity test. The different letters on the error bars indicate significant differences at $P<0.05$ according to Tukey's honestly significant difference test.

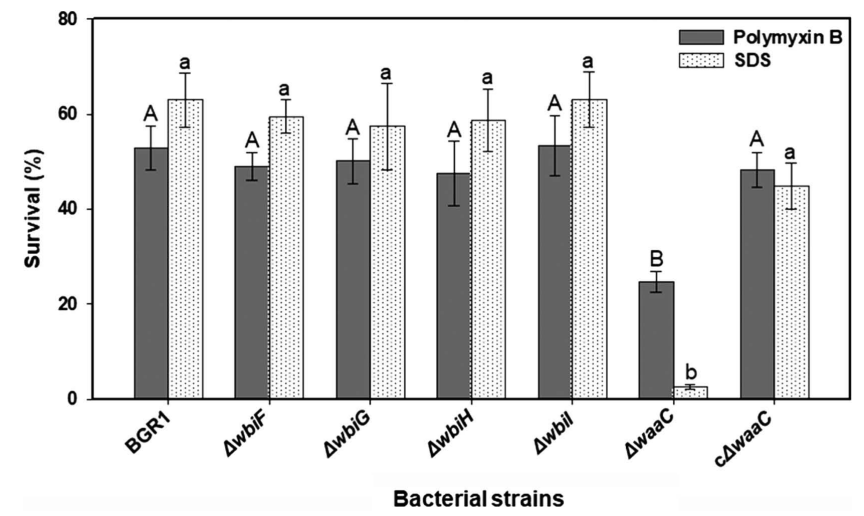

Fig. 4. Burkholderia glumae lipopolysaccharide role in resistance to antibiotic and detergent stress. The wild-type BGR1 and the mutant strains $\Delta w b i F, \Delta w b i G, \Delta w b i H, \Delta w b i I, \Delta w a a C$, and $\mathrm{c} \Delta w a a C$ were tested for resistance to the antimicrobial peptide polymyxin $B$ and to detergent stress from sodium dodecyl sulfate (SDS). Cultures of each strain were treated with $5 \mu \mathrm{g} / \mathrm{ml}$ polymyxin B or $0.01 \%$ SDS and incubated for 30 or $10 \mathrm{~min}$, respectively, then survival rates were estimated. The survival rate of the core oligosaccharide biosynthesis-related $\triangle w a a C$ mutant was significantly lower compared to the other strains. The complementary strain, $\mathrm{c} \Delta$ waaC, restored resistance, which was comparable to that of wild-type BGR1. The different uppercase and lowercase letters on error bars represent significant differences in bacterial survival rate in the presence of polymyxin B and SDS, respectively, according to Tukey's honestly significant difference test at $P<0.05$. 

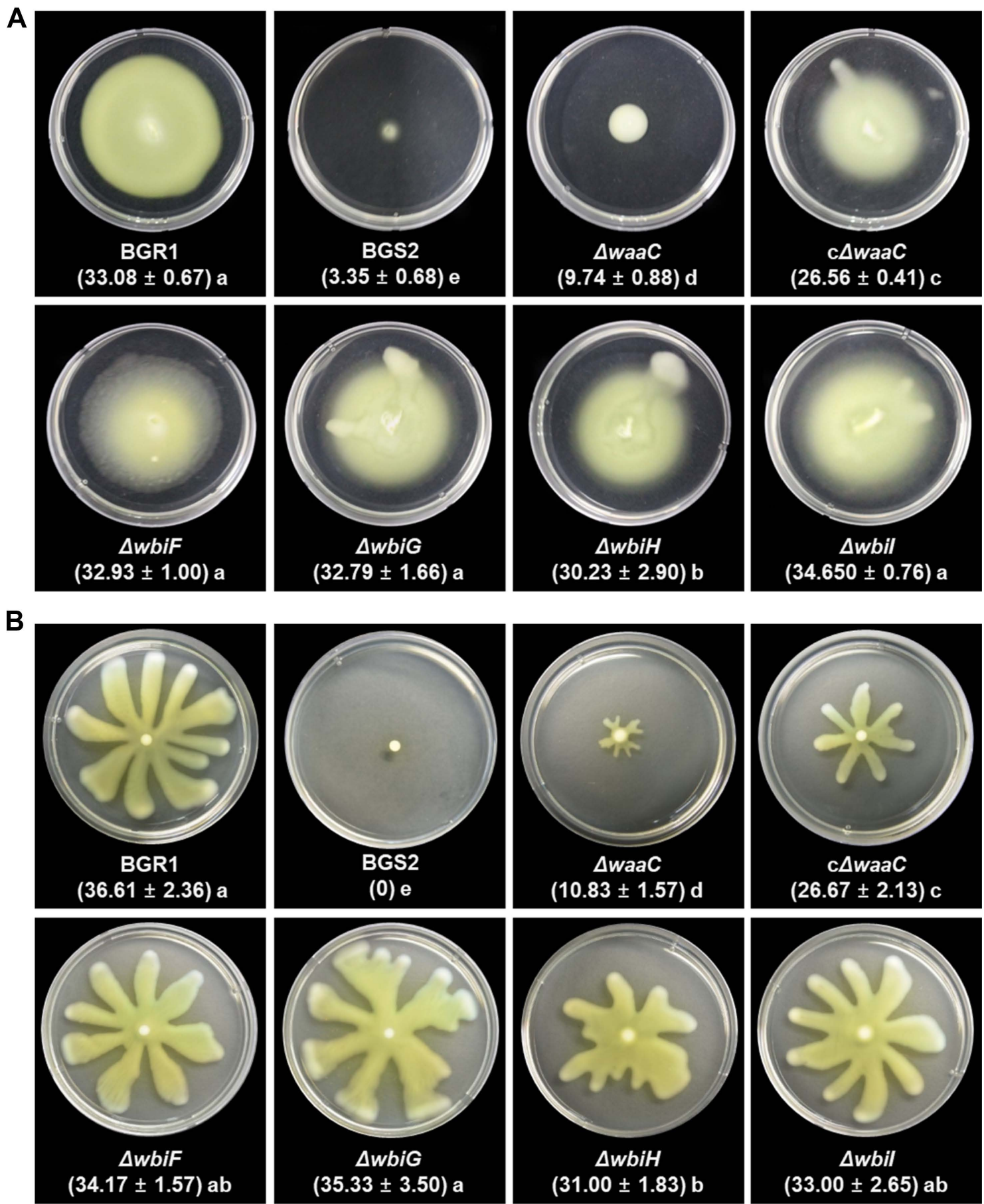

Fig. 5. The role of lipopolysaccharide in Burkholderia glumae motility. (A) The swimming motility of the wild-type BGR1 and mutant strains $\Delta w b i F, \Delta w b i G, \Delta w b i H, \Delta w b i I, \Delta w a a C$, and $\mathrm{c} \triangle w a a C$ was tested on Luria-Bertani (LB) plates containing $0.25 \%$ agar. (B) The swarming motility was tested on LB plates containing $0.4 \%$ agar. The swimming and swarm radius (cm) for each strain was estimated $24 \mathrm{~h}$ after incubation as an average of the dendrite measurements from each plate (a replicate). The swimming and swarming motility of the four O-antigen mutants was not significantly different compared to that of the wild-type BGR1, except for $\Delta w b i H$, which showed a slightly reduced motility. The strongest effect on motility was observed in the core oligosaccharide-related mutant $\Delta w a a C$, displaying a great reduction compared to the other strains. The complementary strain, $\mathrm{c} \Delta w a a C$, partially restored the swarming motility. The quorum sensing-defective mutant BGS2 was used as a negative control in both assays. The different letters following the mean radius \pm standard deviation, indicate significant differences according to Tukey's honestly significant difference test at $P<0.05$. 


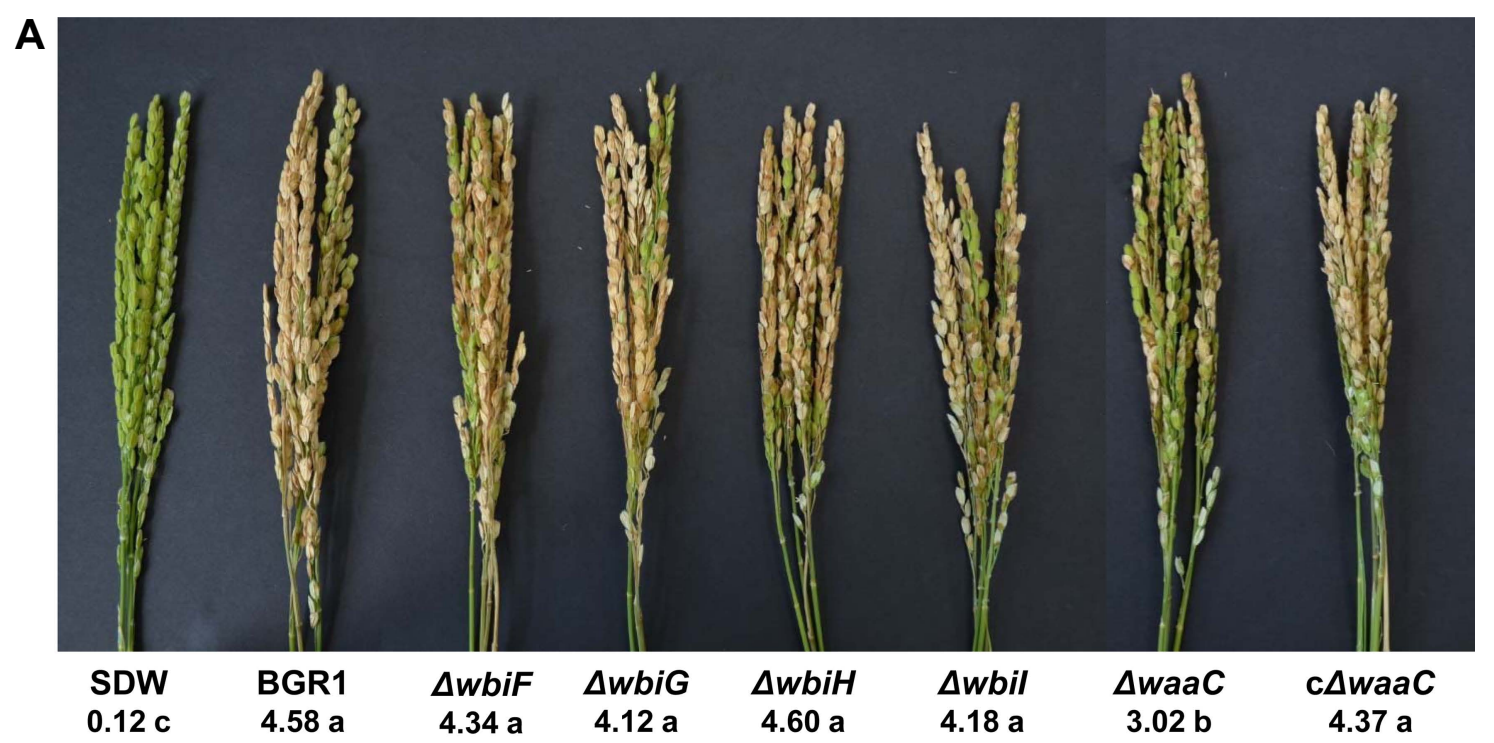

B

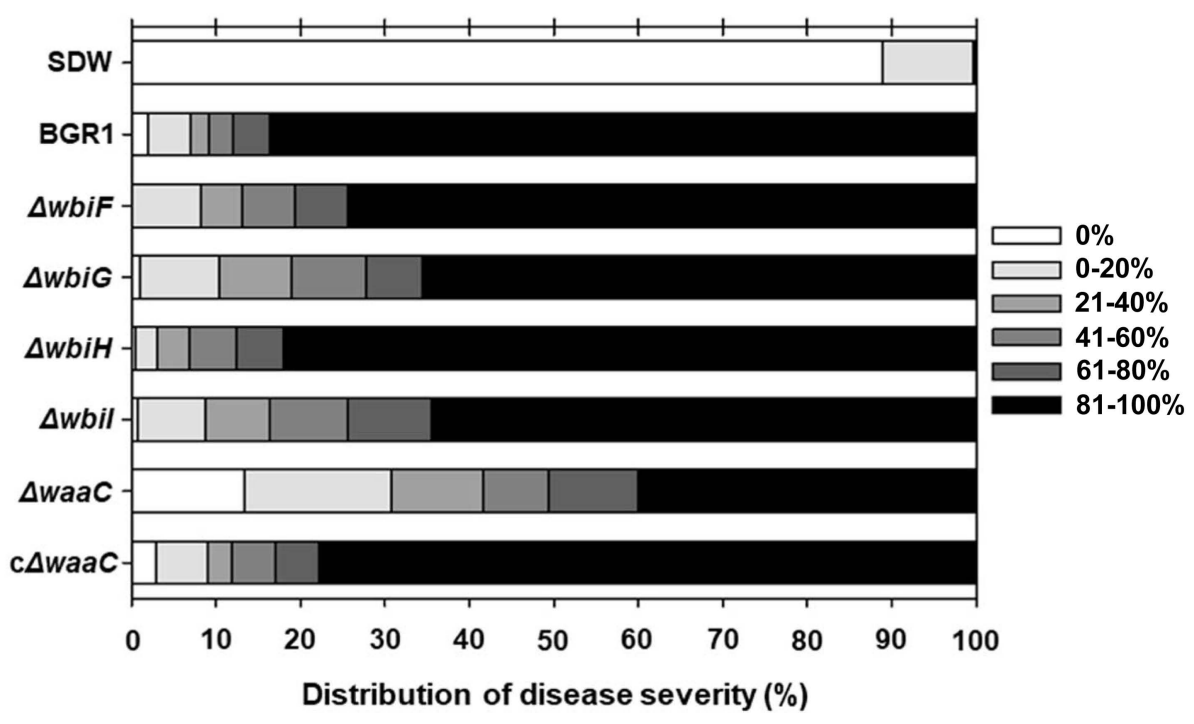

Fig. 6. The role of lipopolysaccharide in Burkholderia glumae virulence to rice. Disease severity on rice plants was assessed 5 days after inoculation by dipping in sterile distilled water (SDW, control) or in cultures of the O-antigen mutants $\Delta w b i F, \Delta w b i G, \Delta w b i H, \Delta w b i I$, the core oligosaccharide (OS) biosynthesis-related $\triangle$ waaC mutant, or its complemented strain, $\mathrm{c} \triangle W A A C$. (A) Photographs of the rice panicles at the time of disease severity assessment. The mean values of disease severity rank (0-5) are shown, followed by letters representing the significant differences according to Tukey's honestly significant difference test at $P<0.05$. (B) Stacked bar graph representing the distribution patterns of disease severity for each treatment. Disease severity was significantly reduced only with the core OS biosynthesis-related $\triangle$ waaC mutant treatment and was restored by the complementary strain, $\mathrm{c} \Delta$ waaC.

to the other mutants $(\Delta w b i F, \Delta w b i G, \Delta w b i H$, and $\triangle w b i I)$ and the wild-type strain (BGR1). A partial recovery of the swimming and swarming motility were observed in the complemented strain, $\mathrm{c} \triangle w a a C$. The $\triangle w b i H$ mutant showed slightly reduced swimming and swarming motility compared to the wild-type, with significantly reduced swimming and swarm diameters. The negative control, i.e., the QS-defective mutant BGS2, showed almost complete loss of the swimming and swarming motility (Fig. 5). These results indicated the requirement of functional WaaC protein for swarming motility in B. glumae BGR1.

The LPS core OS is required for full virulence of $B$. glumae to rice plants. To finally investigate the effect of disruption in the targeted LPS-related genes on B. glumae BGR1 virulence to rice, rice assays were performed using 
the constructed mutants compared to wild-type. The observation of inoculated rice panicles indicated that a clear reduction in the blight symptoms, compared to the wildtype BGR1, only occurred upon inoculation of the $\triangle$ waaC mutant, whereas the other mutants $(\triangle w b i F, \triangle w b i G, \triangle w b i H$, and $\Delta w b i l$ ) caused similar symptoms as the wild-type strain (Fig. 6A). This observation was confirmed by the assessment of disease severity and distribution pattern, showing a significant reduction in the disease severity rank after treatment with the $\triangle w a a C$ strain (Fig. 6A and B). The complemented strain, $\mathrm{c} \triangle$ waa , showed complete virulence recovery. The negative control rice plants treated with SDW did not display any blight symptoms. These results indicated that the core OS-related gene, waaC, was required for the full virulence of B. glumae BGR1 to rice plants.

\section{Discussion}

To study the functions of LPS in B. glumae, mutants targeting the $\mathrm{O}$-antigen and the core OS biosynthesis-related genes were generated, and their phenotype was characterized. A study in Burkholderia cenocepacia proposed the following functions for the genes belonging to the wbiF$G H I$ operon involved in O-antigen biosynthesis: wbiF, glycosyltransferase; wbiG, nucleotide sugar epimerasedehydratase; wbiH, UDP-UDP-N-acetylglucosamine 1-P transferase; and wbil, nucleotide sugar epimerasedehydratase (Ortega et al., 2005). Although other genes are involved in the O-antigen biosynthesis, the wbiFGHI operon is a fundamental part of the O-antigen gene cluster, encoding enzymes that are essential for O-antigen biosynthesis and assembly (Ortega et al., 2005). The targeted gene for core OS was waaC, which is part of the core OS gene locus, the most conserved across the Burkholderia genus. The waaC encodes heptosyltransferase I, which functions by adding heptose to the inner core in an early stage of the core OS biosynthesis pathway (Gronow et al., 2000; Ortega et al., 2005; Wang et al., 2015).

The effect of the induced mutations was verified by comparing the associated LPS profiles to that of the wildtype strain. The wbiFGHI mutants exhibited a reduced Oantigen region and an increased production of the core and lipid A, whereas the waaC mutant exerted a clear detrimental effect on the LPS synthesis, mainly a truncated lipid A core. Chemical alteration of the core OS structure and reduced length of the $\mathrm{O}$-antigen region were also previously reported as a consequence of waaC gene mutations in the insect symbiont Burkholderia sp. (Kim et al., 2017). In our study on B. glumae, the impact of waaC disruption on LPS structure was stronger compared to that of $\mathrm{O}$-antigen- affecting wbiFGHI mutations. The phenotypic characterization showed that waaC disruption was associated with impaired bacterial resistance to environmental stress conditions, loss of motility, and attenuation of virulence to rice plants. On the other hand, the wbiFGHI mutants did not display significant phenotypic effects, except for a partial inhibition of swarming motility caused by $w b i H$ deletion. Bacteria were apparently able to recover from, or tolerate, partial O-antigen losses due to single gene disruption without significant impairment of cellular functions related to adaptation to harsh environment and virulence.

EPS is generally considered as a bacterial virulence factor particularly in wilt-causing xylem-colonizing phytopathogens (Denny, 1995). B. glumae was previously reported to cause wilting symptoms in many other crops in addition to rice, and EPS could be the virulence factor responsible for occlusion of the plant vascular system in these cases (Ham et al., 2011). Wang et al. (2013) reported that mutation in one enzyme involved in LPS synthesis resulted in moderate impairment of EPS accumulation, thus reducing the virulence of $X$. oryzae pv. oryzicola. On the contrary, our results showed no significant differences in EPS production between the generated B. glumae mutants and the wild-type strain.

One of the best-known functions of the bacterial outer membrane is the tolerance to environmental stress and antibiotics. Our results showed that the core OS mutant, deficient in the waaC gene, was particularly sensitive to different stress conditions, unlike the $\mathrm{O}$-antigen-deficient mutants defective in wbiFGHI genes, which did not exhibit significant changes in their sensitivity to such environmental stress conditions nor to the antimicrobial peptide. These results came in accordance with previous studies reporting a significant increase in the bacterial sensitivity to different environmental stress condition and antibiotics as a consequence of mutations in genes for LPS synthesis, particularly the core OS biosynthesis-related genes (Berry et al., 2009; Kong et al., 2011; Loutet et al., 2006; Møller et al., 2003).

Mutations in the core OS biosynthesis-related genes displayed a hypersensitivity to SDS detergent and salt stress in E. coli (Møller et al., 2003). Similarly, in Salmonella enterica, mutations in LPS-related genes resulted in higher sensitivity to detergent stress and polymyxin B (Kong et al., 2011). In addition, mutations in two genes involved in core OS biosynthesis in a related strain of $B$. cenocepacia resulted in increased sensitivity to polymyxin $B$, as well as to structurally distinct antimicrobial peptides (Loutet et al., 2006; Ortega et al., 2009).

Previous studies have reported a link between the core 
OS biosynthesis-related waaC and expression of the outer membrane protein A (OmpA) (Beher and Schnaitman, 1981). OmpA is an abundant protein of the outer membrane, suggested to be important for membrane barrier properties and structural integrity, which in turn are required for protection against stress conditions such as acidity (Rowbury, 2004; Vivijs et al., 2016). This finding could explain, in part, the increased sensitivity to acidic stress that we observed in the waaC-defective mutant. Nevertheless, unlike the other tested stress conditions, the bacterial sensitivity to $\mathrm{H}_{2} \mathrm{O}_{2}$ was not affected by any of the mutations generated in the current study. However, increased sensitivity to oxidative stress was previously reported in an Erwinia amylovora mutant defective in LPS biosynthesis (Berry et al., 2009). Thus, LPS might have different functions in distinct bacterial genera.

Bacterial motility is another key factor for virulence to host plants, as it facilitates the migration of bacteria, allowing them to reach infection sites. In a non-motile $B$. glumae mutant that normally produces toxoflavin, the major virulence factor, bacterial virulence was found to be compromised, highlighting the importance of motility in this process (Kim et al., 2007). Bacterial motility is highly sensitive to the surrounding environment, which affects the development of flagella (Jang et al., 2014; McCarter, 2006). Moreover, LPS structural deficiency, especially in the core OS, was reported to alter the regulation of gene expression through the Rcs phosphorelay system. The latter is a cell stress-response system allowing bacterial cells to sense stress conditions via changes in the outer membrane. It consists of a cascade of reactions initially involving a membrane lipoprotein and ultimately regulating the expression of specific genes (Huang et al., 2006; Ren et al., 2016). Several studies reported that activation of the Rcs signaling system inhibits the transcription of the flhDC master operon, which is involved in the assembly of flagella and, thus, is crucial for swimming and swarming motility (FrancezCharlot et al., 2003; Wang and Harshey, 2009). In light of these findings, the structural changes associated with the waaC mutation in the current study could have affected the expression of genes involved in the development of flagella, resulting in impaired motility. Consistently, the insect symbiont $w a a C$-defective mutant was previously shown to display reduced motility (Kim et al., 2017).

Finally, the impact of gene disruption affecting O-antigen and core OS biosynthesis on bacterial virulence to rice plants was tested. The impact of defective core OS synthesis on B. glumae virulence could be attributed to several factors, including inhibition of bacterial motility, as well as impaired tolerance to environmental stress. Tolerance to such stress conditions is particularly important for the survival of B. glumae both in its natural environment, the soil, and inside the host plants, which produce defense-related compounds in response to pathogen infection. In rice plants, the recognition of LPS from pathogenic and nonpathogenic bacteria was shown to trigger the production of reactive oxygen species and the expression of defenserelated genes (Desaki et al., 2006). Furthermore, a previous study has reported the role of an LPS-related gene, $w z y B$, as a potential genetic signaling component independent from the quorum sensing, in the production of toxoflavin, the major virulence factor of B. glumae (Chen et al., 2015).

The complemented strain $\mathrm{c} \Delta$ waaC, have shown complete recovery of bacterial virulence to rice plants, although the same strain showed only partial recovery of bacterial motility compared to the $\triangle w a a C$ strain. These results indicate that although waaC is important for bacterial motility, other factors could be involved. For the bacterial virulence, bacterial motility plays a role in full virulence along with the bacterial ability to tolerate the host defense and other environmental stress. Therefore, full virulence was recovered in the complemented strain $\mathrm{c} \triangle w a a C$, not only because of the recovery of motility but also the recovery of bacterial tolerance to different stress conditions.

In conclusion, to our knowledge, this is the first study to investigate the roles of LPS in B. glumae. The results revealed the requirement of the core OS for environmental stress resistance, swimming and swarming motility, and virulence. However, the deletion of any gene of the O-antigen biosynthesis-related wbiFGHI operon did not affect the bacterial sensitivity to environmental stress nor virulence to rice. This could be due to the bacterial ability to overcome the partial loss of repeating units in the O-antigen region, or to structural changes that prevent or revert outer membrane instability. The association of the core OS-related gene waaC with the outer membrane protein or the Res phosphorelay system could be linked to the observed impact on bacterial motility, tolerance to environmental stress and consequently bacterial virulence to rice. Further studies are required to elucidate the molecular mechanisms by which rice plant cells recognize and respond to $B$. glumae LPS, thus enhancing our comprehension of $B$. glumae pathogenesis.

\section{Acknowledgments}

This research was supported by the Basic Science Research Program through the National Research Foundation of Korea (NRF) funded by the Ministry of Education (2016R1D1A1B03930678) and by grants from the Strategic Initiative 
for Microbiomes in Agriculture and Food, Ministry of Agriculture, Food and Rural Affairs, Republic of Korea (No. 918019-04-1-HD030).

\section{Electronic Supplementary Material}

Supplementary materials are available at Plant Pathology Journal website (http://www.ppjonline.org/).

\section{References}

Beher, M. G. and Schnaitman, C. A. 1981. Regulation of the OmpA outer membrane protein of Escherichia coli. J. Bacteriol. 147:972-985.

Berry, M. C., McGhee, G. C., Zhao, Y. and Sundin, G. W. 2009. Effect of a waaL mutation on lipopolysaccharide composition, oxidative stress survival, and virulence in Erwinia amylovora. FEMS Microbiol. Lett. 291:80-87.

Castelli, M. E., Fedrigo, G. V., Clementín, A. L., Ielmini, M. V., Feldman, M. F. and Véscovi, E. G. 2008. Enterobacterial common antigen integrity is a checkpoint for flagellar biogenesis in Serratia marcescens. J. Bacteriol. 190:213-220.

Chen, R., Barphagha, I. K. and Ham, J. H. 2015. Identification of potential genetic components involved in the deviant quorumsensing signaling pathways of Burkholderia glumae through a functional genomics approach. Front. Cell. Infect. Microbiol. 5:22.

Chun, H., Choi, O., Goo, E., Kim, N., Kim, H., Kang, Y., Kim, J., Moon, J. S. and Hwang, I. 2009. The quorum sensingdependent gene katG of Burkholderia glumae is important for protection from visible light. J. Bacteriol. 191:4152-4157.

Denny, T. P. 1995. Involvement of bacterial polysaccharides in plant pathogenesis. Annu. Rev. Phytopathol. 33:173-197.

Desaki, Y., Miya, A., Venkatesh, B., Tsuyumu, S., Yamane, H., Kaku, H., Minami, E. and Shibuya, N. 2006. Bacterial lipopolysaccharides induce defense responses associated with programmed cell death in rice cells. Plant Cell Physiol. 47:1530-1540.

Dong, H., Tang, X., Zhang, Z. and Dong, C. 2017. Structural insight into lipopolysaccharide transport from the gramnegative bacterial inner membrane to the outer membrane. Biochim. Biophys. Acta Mol. Cell Biol. Lipids 1862:14611467.

Dow, J. M., Osbourn, A. E., Wilson, T. J. G. and Daniels, M. J. 1995. A locus determining pathogenicity of Xanthomonas campestris is involved in lipopolysaccharide biosynthesis. Mol. Plant-Microbe Interact. 8:768-777.

Finnegan, T., Steenkamp, P. A., Piater, L. A. and Dubery, I. A. 2016. The lipopolysaccharide-induced metabolome signature in Arabidopsis thaliana reveals dynamic reprogramming of phytoalexin and phytoanticipin pathways. PLoS ONE 11:e0163572.

Francez-Charlot, A., Laugel, B., Van Gemert, A., Dubarry, N.,
Wiorowski, F., Castanié-Cornet, M.-P., Gutierrez, C. and Cam, K. 2003. RcsCDB His-Asp phosphorelay system negatively regulates the flhDC operon in Escherichia coli. Mol. Microbiol. 49:823-832.

Gronow, S., Brabetz, W. and Brade, H. 2000. Comparative functional characterization in vitro of heptosyltransferase I (WaaC) and II (WaaF) from Escherichia coli. Eur. J. Biochem. 267:6602-6611.

Ham, J. H., Melanson, R. A. and Rush, M. C. 2011. Burkholderia glumae: next major pathogen of rice? Mol. Plant Pathol. 12:329-339.

Hamad, M. A., Di Lorenzo, F., Molinaro, A. and Valvano, M. A. 2012. Aminoarabinose is essential for lipopolysaccharide export and intrinsic antimicrobial peptide resistance in Burkholderia cenocepacia. Mol. Microbiol. 85:962-974.

He, Y.-W., Wu, J., Cha, J.-S. and Zhang, L.-H. 2010. Rice bacterial blight pathogen Xanthomonas oryzae pv. oryzae produces multiple DSF-family signals in regulation of virulence factor production. BMC Microbiol. 10:187.

Hendrick, C. A. and Sequeira, L. 1984. Lipopolysaccharidedefective mutants of the wilt pathogen Pseudomonas solanacearum. Appl. Environ. Microbiol. 48:94-101.

Holst, O. 2007. The structures of core regions from enterobacterial lipopolysaccharides: an update. FEMS Microbiol. Lett. 271:3-11.

Huang, Y.- H., Ferrières, L. and Clarke, D. J. 2006. The role of the Rcs phosphorelay in Enterobacteriaceae. Res. Microbiol. 157:206-212.

Jang, M. S., Goo, E., An, J. H., Kim, J. and Hwang, I. 2014. Quorum sensing controls flagellar morphogenesis in Burkholderia glumae. PLoS ONE 9:e84831.

Jeong, Y., Cheong, H., Choi, O., Kim, J. K., Kang, Y., Kim, J., Lee, S., Koh, S., Moon, J. S. and Hwang, I. 2011. An HrpBdependent but type III-independent extracellular aspartic protease is a virulence factor of Ralstonia solanacearum. Mol. Plant Pathol. 12:373-380.

Jeong, Y., Kim, J., Kim, S., Kang, Y., Nagamatsu, T. and Hwang I. 2003. Toxoflavin produced by Burkholderia glumae causing rice grain rot is responsible for inducing bacterial wilt in many field crops. Plant Dis. 87:890-895.

Jung, B., Park, J., Kim, N., Li, T., Kim, S., Bartley, L. E., Kim, J., Kim, I., Kang, Y., Yun, K., Choi, Y., Lee, H.-H., Ji, S., Lee, K. S., Kim, B. Y., Shon, J. C., Kim, W. C., Liu, K.-H., Yoon, D., Kim, S., Seo, Y.-S. and Lee, J. 2018. Cooperative interactions between seed-borne bacterial and air-borne fungal pathogens on rice. Nat. Commun. 9:31.

Kalogeraki, V. S. and Winans, S. C. 1997. Suicide plasmids containing promoterless reporter genes can simultaneously disrupt and create fusions to target genes of diverse bacteria. Gene 188:69-75.

Keen, N. T., Tamaki, S., Kobayashi, D. and Trollinger, D. 1988. Improved broad-host-range plasmids for DNA cloning in gram-negative bacteria. Gene 70:191-197.

Kim, J. K., Jang, H. A., Kim, M. S., Cho, J. H., Lee, J., Di Lo- 
renzo, F., Sturiale, L., Silipo, A., Molinaro, A. and Lee, B. L. 2017. The lipopolysaccharide core oligosaccharide of Burkholderia plays a critical role in maintaining a proper gut symbiosis with the bean bug Riptortus pedestris. J. Biol. Chem. 292:19226-19237

Kim, J., Kang, Y., Choi, O., Jeong, Y., Jeong, J.-E., Lim, J. Y., Kim, M., Moon, J. S., Suga, H. and Hwang, I. 2007. Regulation of polar flagellum genes is mediated by quorum sensing and FlhDC in Burkholderia glumae. Mol. Microbiol. 64:165179.

Kim, J., Kim, J.-G., Kang, Y., Jang, J. Y., Jog, G. J., Lim, J. Y., Kim, S., Suga, H., Nagamatsu, T. and Hwang, I. 2004. Quorum sensing and the LysR-type transcriptional activator ToxR regulate toxoflavin biosynthesis and transport in Burkholderia glumae. Mol. Microbiol. 54:921-934.

Kim, J., Mannaa, M., Kim, N., Lee, C., Kim, J., Park, J., Lee, H.-H. and Seo, Y.-S. 2018. The roles of two $h f q$ genes in the virulence and stress resistance of Burkholderia glumae. Plant Pathol. J. 34:412-425.

King, K. Y., Horenstein, J. A. and Caparon, M. G. 2000. Aerotolerance and peroxide resistance in peroxidase and PerR mutants of Streptococcus pyogenes. J. Bacteriol. 182:5290-5299.

Kong, Q., Yang, J., Liu, Q., Alamuri, P., Roland, K. L. and Curtiss, R. 3rd. 2011. Effect of deletion of genes involved in lipopolysaccharide core and $\mathrm{O}$-antigen synthesis on virulence and immunogenicity of Salmonella enterica serovar Typhimurium. Infect. Immun. 79:4227-4239.

Kovach, M. E., Elzer, P. H., Hill, D. S., Robertson, G. T., Farris, M. A., Roop, R. M. and Peterson, K. M. 1995. Four new derivatives of the broad-host-range cloning vector $\mathrm{pBBR} 1 \mathrm{MCS}$, carrying different antibiotic-resistance cassettes. Gene 166:175-176.

Kutschera, A. and Ranf, S. 2018. The multifaceted functions of lipopolysaccharide in plant-bacteria interactions. Biochimie 159:93-98.

Lee, J., Park, J., Kim, S., Park, I. and Seo, Y.-S. 2016. Differential regulation of toxoflavin production and its role in the enhanced virulence of Burkholderia gladioli. Mol. Plant Pathol. 17:65-76.

Lelis, T., Peng, J., Barphagha, I., Chen, R. and Ham, J. H. 2019. The virulence function and regulation of the metalloprotease gene prtA in the plant-pathogenic bacterium, Burkholderia glumae. Mol. Plant-Microbe Interact. 32:841-852.

Levene, H. 1960. Robust tests for equality of variances. In: Contributions to probability and statistics: essays in honor of Harold Hotelling, eds. by I. Olkin, S. G. Ghurye, W. Hoeffding, W. G. Madow and H. B. Mann, pp. 278-292. Stanford University Press, Palo Alto, CA, USA.

Li, J. and Wang, N. 2011. The wxacO gene of Xanthomonas citri ssp. citri encodes a protein with a role in lipopolysaccharide biosynthesis, biofilm formation, stress tolerance and virulence. Mol. Plant Pathol. 12:381-396.

Loutet, S. A., Flannagan, R. S., Kooi, C., Sokol, P. A. and Valvano, M. A. 2006. A complete lipopolysaccharide inner core oligosaccharide is required for resistance of Burkholderia cenocepacia to antimicrobial peptides and bacterial survival in vivo. J. Bacteriol. 188:2073-2080.

Mannaa, M., Park, I. and Seo, Y.-S. 2019. Genomic features and insights into the taxonomy, virulence, and benevolence of plant-associated Burkholderia species. Int. J. Mol. Sci. 20:121.

McCarter, L. L. 2006. Regulation of flagella. Curr. Opin. Microbiol. 9:180-186.

Møller, A. K., Leatham, M. P., Conway, T., Nuijten, P. J. M., de Haan, L. A. M., Krogfelt, K. A. and Cohen, P. S. 2003. An Escherichia coli MG1655 lipopolysaccharide deep-rough core mutant grows and survives in mouse cecal mucus but fails to colonize the mouse large intestine. Infect. Immun. 71:2142-2152.

Nakao, R., Ramstedt, M., Wai, S. N. and Uhlin, B. E. 2012. Enhanced biofilm formation by Escherichia coli LPS mutants defective in Hep biosynthesis. PLoS ONE 7:e51241.

Newman, M.-A., Sundelin, T., Nielsen, J. T. and Erbs, G. 2013. MAMP (microbe-associated molecular pattern) triggered immunity in plants. Front. Plant Sci. 4:139.

Ortega, X., Hunt, T. A., Loutet, S., Vinion-Dubiel, A. D., Datta, A., Choudhury, B., Goldberg, J. B., Carlson, R. and Valvano, M. A. 2005. Reconstitution of O-specific lipopolysaccharide expression in Burkholderia cenocepacia strain J2315, which is associated with transmissible infections in patients with cystic fibrosis. J. Bacteriol. 187: 1324-1333.

Ortega, X., Silipo, A., Saldías, M. S., Bates, C. C., Molinaro, A. and Valvano, M. A. 2009. Biosynthesis and structure of the Burkholderia cenocepacia K56-2 lipopolysaccharide core oligosaccharide. truncation of the core oligosaccharide leads to increased binding and sensitivity to polymyxin B. J. Biol. Chem. 284:21738-21751.

Park, B. S. and Lee, J.-O. 2013. Recognition of lipopolysaccharide pattern by TLR4 complexes. Exp. Mol. Med. 45:e66.

Ren, G., Wang, Z., Li, Y., Hu, X. and Wang, X. 2016. Effects of lipopolysaccharide core sugar deficiency on colanic acid biosynthesis in Escherichia coli. J. Bacteriol. 198:1576-1584.

Rowbury, R. J. 2004 Enterobacterial responses to external protons, including responses that involve early warning against stress and the functioning of extracellular pheromones, alarmones and varisensors. Sci. Prog. 87:193-225.

Sambrook, J., Fritsch, E. F. and Maniatis, T. 1989. Molecular cloning: a laboratory manual. 2nd ed. Cold Spring Harbor Laboratory Press, Cold Spring Harbor, NY, USA. 1626 pp.

Schäfer, A., Tauch, A., Jäger, W., Kalinowski, J., Thierbach, G. and Pühler, A. 1994. Small mobilizable multi-purpose cloning vectors derived from the Escherichia coli plasmids $\mathrm{pK} 18$ and pK19: selection of defined deletions in the chromosome of Corynebacterium glutamicum. Gene 145:69-73.

Schoonejans, E., Expert, D. and Toussaint, A. 1987. Characterization and virulence properties of Erwinia chrysanthemi lipopolysaccharide-defective, phi EC2-resistant mutants. $J$. Bacteriol. 169:4011-4017. 
Simon, R., Priefer, U. and Pühler, A. 1983. A broad host range mobilization system for in vivo genetic engineering: transposon mutagenesis in gram-negative bacteria. Nat. Biotechnol. 1:784-791.

Sperandeo, P., Martorana, A. M. and Polissi, A. 2017. Lipopolysaccharide biogenesis and transport at the outer membrane of Gram-negative bacteria. Biochim. Biophys. Acta Mol. Cell Biol. Lipids 1862:1451-1460.

Vilakazi, C. S., Dubery, I. A. and Piater, L. A. 2017. Identification of lipopolysaccharide-interacting plasma membrane-type proteins in Arabidopsis thaliana. Plant Physiol. Biochem. 111:155-165.

Vivijs, B., Aertsen, A. and Michiels, C. W. 2016. Identification of genes required for growth of Escherichia coli MG1655 at moderately low pH. Front. Microbiol. 7:1672.

Wang, L., Vinogradov, E. V. and Bogdanove, A. J. 2013. Requirement of the lipopolysaccharide $\mathrm{O}$-chain biosynthesis gene $w x o c B$ for type III secretion and virulence of Xanthomonas oryzae pv. Oryzicola. J. Bacteriol. 195:1959-1969.

Wang, Q. and Harshey, R. M. 2009. Rcs signalling-activated transcription of $\operatorname{rcs} A$ induces strong anti-sense transcription of upstream fliPQR flagellar genes from a weak intergenic promoter: regulatory roles for the anti-sense transcript in virulence and motility. Mol. Microbiol. 74:71-84.

Wang, Z., Wang, J., Ren, G., Li, Y. and Wang, X. 2015. Influence of core oligosaccharide of lipopolysaccharide to outer membrane behavior of Escherichia coli. Mar. Drugs 13:33253339.

Westphal, O. 1965. Bacterial lipopolysaccharides extraction with phenol-water and further applications of the procedure. Methods Carbohydr. Chem. 5:83-91.

Zeidler, D., Zähringer, U., Gerber, I., Dubery, I., Hartung, T., Bors, W., Hutzler, P. and Durner, J. 2004. Innate immunity in Arabidopsis thaliana: lipopolysaccharides activate nitric oxide synthase (NOS) and induce defense genes. Proc. Natl. Acad. Sci. U. S. A. 101:15811-15816. 